\title{
Early Design Decision-Making Framework Based on Multi-Objective Building Performance Simulation Incorporating Energy, Carbon Footprint and Cost
}

\author{
Allison Bernett ${ }^{1}$, Timur Dogan ${ }^{1}$ \\ ${ }^{1,2}$ Environmental Systems Lab, Cornell University, Ithaca, New York, USA
}

\begin{abstract}
Given the substantial energy and carbon footprint of buildings worldwide, building simulation technology continually strives to facilitate high-performance designs, yet many simulation tools inform building construction only after major design decisions have been made. Alternatively, early design simulation tools help design teams embed energy and environmental performance into the core design. This paper presents an EnergyPlus-based early design decision-making framework for building simulation that when furnished with basic inputs generates design options that can be filtered by energy performance, carbon footprint, and cost criteria. The framework is used to inform the design of hypothetical eight-story office buildings in Washington D.C. and Phoenix, AZ, USA. This framework aims to assist architects in developing and refining high-performance preliminary designs based on their project and budgetary constraints.
\end{abstract}

\section{Introduction}

With the reality of climate change, cities and municipalities across the globe are attempting to reduce their carbon footprints. In the past year, Copenhagen, London, Montreal, New York City, Paris, Stockholm, Sydney, Tokyo, Tshwane, and ten other cities pledged to ensure all buildings in their cities will meet net-zero carbon standards by 2050 (C40, 2018).

Much research has been dedicated to improving building energy simulation tools and technology to aid in the design of high-performance buildings. However, the vast majority of this research has focused on tools and models that suggest improvements to highly resolved designs. One study found that of the 400 building energy simulation tools listed on the U.S. Department of Energy's website in 2013, less than 8\% of them had the potential to inform the pre-design phases (Batueva and Mahdavi, 2014). This conventional design process can miss opportunities to significantly improve energy performance and reduce cost through simple design modifications. Alternatively, tools intended to aid architects and design teams during pre-design and schematic design stages can lead to high-performance designs through a more integrated process (Hygh, DeCarolis, Hill, and Ranji Ranjithan, 2012; Østergård, Jensen, and Maagaard, 2016).

Most building performance simulation software can only evaluate refined designs, are difficult to modify quickly if the design changes, and are not user-friendly for architects (Attia, Gratia, De Herde, and Hensen, 2012; Østergård et al., 2016). Thus, simulation software intended for the early design phases must have different qualities than typical building simulation software. A recent review of building simulation software asserts that early stage design simulation software should be proactive, intelligent, capable of accommodating rapid design changes, and holistic (Østergård et al., 2016). Proactive software is especially crucial since it provides multiple design options instead of evaluating an existing design. A survey of architects and engineers found that architects prioritize intelligence, or the ability to support decisionmaking throughout the design phases, in simulation software over usability, accuracy, and interoperability (Attia, Hensen, Beltrán, and Herde, 2012). Since architects usually make critical design decisions such as building massing, orientation, and structure that greatly impact the energy and carbon footprint, early design simulation software should ideally cater to architects. Overall, these criteria suggest that a successful early design software should be proactive, intelligent, rapidly adaptable, and architect-friendly.

Some building simulation tools in recent years address this gap in early design simulation software. Attia et al. proposed an early design simulation tool that helps designers select interventions that meet thermal comfort and energy performance goals in hot climates (Attia, Gratia, et al., 2012). Ochoa et al. similarly proposed a predesign tool for intelligent façade design that takes into account aesthetic design requirements like view direction and open or closed office configurations that would impact the façade (Ochoa and Capeluto, 2009). Østergård et al. presented a simulation methodology to help design teams select designs optimized for energy efficiency, thermal comfort, and daylighting in the early phases (Østergård, Jensen, and Maagaard, 2017). Although each of these studies presents proactive, intelligent, and flexible approaches that give designers multiple options, they focus on energy performance, and in the case of Østergård et al., still require an experienced modeler to run simulations.

Embodied energy and carbon in buildings receives even less attention from early design building simulation research. One notable study by Eleftheriadis et al. presents an approach to optimize the structure and various building components for lifecycle carbon emissions and costs. The results showed over a $50 \%$ reduction in carbon footprint and a $10 \%$ reduction in lifecycle costs between 
optimized examples, demonstrating the environmental and economic value of models that focus on lifecycle carbon emissions (Eleftheriadis, Schwartz, Raslan, Duffour, and Mumovic, 2018). Given the increasing number of cities targeting carbon neutrality, many design teams will need to consider the full carbon footprint of buildings, not just operational energy use. This approach has a few drawbacks, including that it first focuses on optimizing the structure and then on improving energy performance. It also requires a predetermined massing and structural material, making it more applicable to schematic design than pre-design phases.

The papers discussed thus far describe several intelligent and proactive methodologies for addressing building energy performance and comfort, or in the case of Eleftheriadis et al., carbon footprint and cost. However, none provide an integrated, flexible approach for exploring the optimal energy, carbon, and cost performance concurrently throughout the pre-design and schematic phases of a building project.

This paper presents a proactive, holistic early design decision-making framework that assesses design options based on energy performance, embodied carbon, and cost, allowing architects and design teams to quickly identify basic designs optimized for their specific environmental goals, programming needs, and budget. The framework is implemented in Rhino/Grasshopper, a popular CAD platform (Robert McNeel \& Associates, 2019). It utilizes the EnergyPlus-based simulation engine Archsim (Dogan, 2018) paired with a "shoeboxer" algorithm (Dogan and Reinhart, 2017) to rapidly run energy simulations, and an "autozoner" algorithm (Dogan, Reinhart, and Michalatos, 2016) that allows users to opt for automatically generated ASHRAE 90.1 thermal zoning. These tools enable both brute-force exploration of the parametric design space in several hours or rapid trialling of design options in seconds. The use of the Rhino/Grasshopper platform also allows architects to easily import or model custom building geometry and input it into the simulation. Reinhart et al. used a similar Rhino/Grasshopper set-up as a teaching tool to help architecture students analyse energy models and improve performance (Reinhart, Dogan, Ibarra, and Samuelson, 2012).

Since every design project has unique goals and constraints, this framework does not inherently prioritize one assessment criteria over the other, but instead empowers the design team to select options that fit their goals and constraints. Importantly, the framework is flexible enough for use in pre-design into schematic design phases, assisting architects with key decisions at multiple stages. In essence, this framework is intended to supplement an architects' intuition during early design, fulfilling an underserved function among building performance simulation software.

\section{Methods}

This version of the framework applies only to office buildings ranging from one to twenty stories, with several options for shell constructions and structural systems based on typical constructions in the U.S. as well as "green" and mass timber options that have lower carbon footprints and better environmental performance. The framework's structure can be easily expanded in the future to include other building typologies since it simply requires inputting the relevant cost, carbon, and thermal data into the existing templates. The framework is intended to work throughout the pre-design (programming and analysis phase) and into the schematic design phase of projects. It can be used before massing and other aspects are resolved and then updated with details like the envelope, structure, and orientation as the project progresses

\section{Data Collection \& Organization}

To provide estimates for the building's carbon footprint, energy usage, and cost over time, data was collected from multiple sources, including RSMeans Online, a building cost estimation database (Gordian, 2018), and the Inventory of Carbon and Energy database (ICE), which provides general estimates of the cradle-to-gate embodied carbon and energy per mass of material for common construction materials in the U.K. and globally (Jones and Hammond, 2011).

The data, organized by Uniformat Level 1 categories of the substructure, shell, interiors, services, and equipment \& furnishings, was inputted into building and zone templates, from which embodied carbon and cost for multiple combinations of wall constructions, roof, structure, glazing, and services can be calculated. Figure 1 shows the overall flow of inputs and data to produce simulation results. Data categories like interiors, substructure, and equipment $\&$ furnishings were set to a default "green" or low-environmental impact construction.

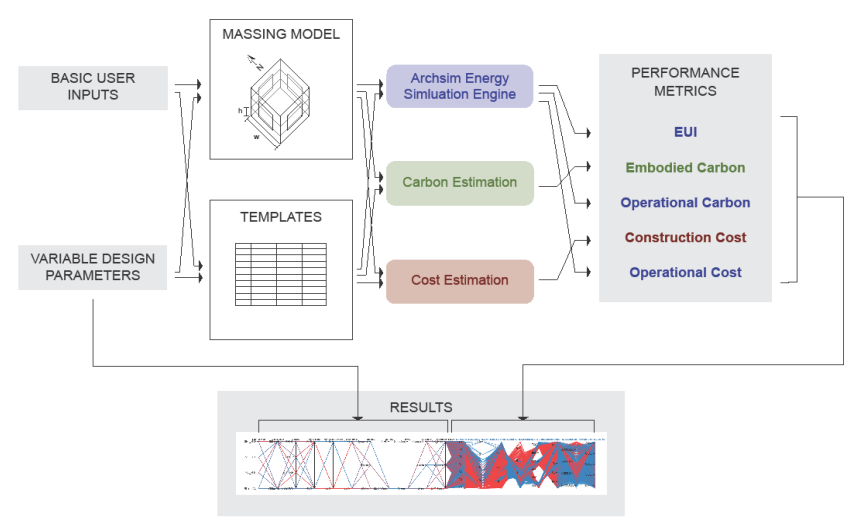

Figure 1: Flowchart of inputs and data for simulation.

The framework expanded the EnergyPlus-based engine Archsim's libraries to include embodied carbon and cost data for materials and assemblies. Cost data originated from RSMeans for the national U.S. average in 2018. RSMean's square foot estimator, which provides cost estimate breakdowns for standard and "green" office building constructions in the U.S., generated most of the cost data. Assumptions included an open shop construction, architectural fees of $8 \%$ and contractor fees of $25 \%$ of the construction cost. Additional data for 
special constructions, such as mass timber and triple pane windows, supplemented the square foot estimations.

Structural system data originated from both RSMeans' square foot estimator and assembly data. Starting with user-specified structure of either concrete, steel framing, or timber framing, the framework uses RSMeans' standard structural elements, configurations, and loads for the material type and range of building stories (1 story, 24 stories, 5-10 stories, and 11-20 stories) to estimate the cost and volume of structural materials per $\mathrm{m}^{2}$ of floor area. This combined with ICE data provided an estimated carbon footprint of the structure. The structural system was assumed to be independent of the exterior envelope.

\section{Simulation}

At the beginning of a project, a brute-force batch run of simulations is conducted for each possible combination of major building components to provide initial estimates using the Grasshopper plugin Colibri (Thornton Tomasetti, n.d.). The results can be outputted to Design Explorer (Thornton Tomasetti, 2017) to generate an interactive parallel access plot for each iteration, which allow users to easily explore and visualize the best initial design options. This first run is computationally expensive since the simulation workload increases exponentially with every building component option considered. However, this method provides the team with a comprehensive understanding of the parametric design space.

As the design progresses, users can set more inputs and customize geometry. Users can either run a smaller set of combinations using Colibri or simulate single designs, both of which can be computed quickly.

\section{User Workflow}

At the beginning of a project, the user inputs at minimum the project's estimated size in square meters, number of stories, and location (either selected from sim EPW files or loaded by the user). From these inputs, the simulation assumes floor plates with an equal area per floor, oriented due south and a story height of 3.66 meters ( 12 feet) for 1-10 stories or 3.05 meters (10 feet) for 11-20 stories.

The framework then simulates all combinations of the variable building parameters, including exterior wall, roof R-value, glazing, structure, window-to-wall ratios, shading, and floorplate shape. The results are compiled in Design Explorer's interactive parallel-axis plot, which allows the user to highlight, sort, or cull results based on the variable inputs or outputs of estimated energy use intensity (EUI), embodied carbon of the materials, operational carbon emissions, construction cost, and operational cost.

As the project progresses, design teams can further manipulate and refine the model to match design details or test alternative options, including specifying HVAC and lighting options. Users can interact directly with the Rhino/Grasshopper interface to either model or import custom building massings and manipulate non-geometric inputs on the Grasshopper canvas. Each of the variable parameters can be narrowed to a smaller range of options or made static, reducing the final field of possible designs.

\section{Case Study: Eight-story Office Building}

To demonstrate how this framework might assist design decisions, a hypothetical eight-story, 1,600 $\mathrm{m}^{2}$ office building was considered for a case study exercise. The building was modelled in two of the major climate zones in the US: Washington D.C., USA (a mixed humid climate) and Phoenix AZ, USA (a hot dry climate). In the first phase, batch runs were conducted to show the full parametric design space of these buildings in both climates. Static parameters included the floor area, number of stories, story height, general construction (which was set to "green"). HVAC (which was set to a COP of 3 for heating and cooling, similar to minimum energy code requirements) and artificial lighting (which was set to LEDs and daylight dimming) were static because they do not depend on geometric parameters yet have significant impacts on EUI. Daylight dimming was turned on so that geometric parameters could be assessed for their impact on daylighting. The full HVAC and lighting options were reintroduced in later phases. Variable parameters included exterior wall construction (Brick and CMU, precast concrete, or plywood structurally insulated panels (SIPs), each with varying Rvalues), structural system (steel, concrete, or timber), roof R-value, glazing type (double pane with a $0.8 \mathrm{SHGC}$ and 2.7 U-value - "Type 1", double pane with a 0.4 SHGC and a 1.5 U-value - "Type 2", double pane with a 0.6 SHGC and a 1.5 U-value - "Type 3", or triple pane with a 0.8 SHGC and a 0.8 U-value - "Type 4"), window-towall ratios (WWRs) of either $30 \%$ or $70 \%$ for the south, east and west, and north facades, exterior shading (none, static, or dynamic), and the floorplate shape (either eastwest rectangle, square, or north-south rectangle - Figure 2 ). Including all the options available in the framework produced over 1.6 million possible design iterations. To reduce the number of iterations and run time, only the extreme options of each parameter were included (e.g. only the lowest and highest R-values for exterior walls and roofs were selected). These ranges were roughly based on standard constructions dictated by RSMeans and energy code and advanced green constructions. Once the design resolved further, more middle ground options were reintroduced.

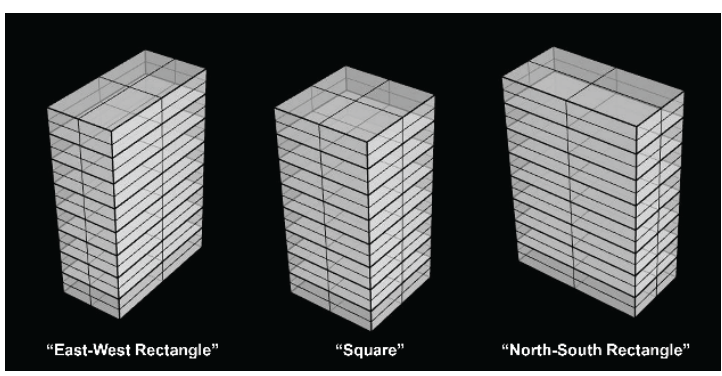

Figure 2: Floorplate shapes used in initial simulations.

The initial runs for Washington D.C. and Phoenix each simulated 10,368 combinations of the above variables. The results were compiled and imported into Design Explorer for analysis.

Based on the results from the initial runs for Phoenix Washington D.C., the building designs were narrowed to 
a few parameters. Four custom massing designs, taking cues from the more successful floorplate shapes for each climate, were inputted into the framework (Figure 3). The simulations were run again, this time with only 256 combinations per massing design. Results were compared in Design Explorer.

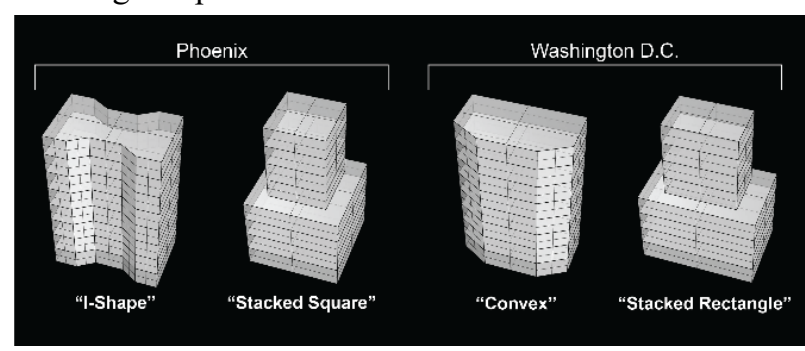

Figure 3: Four custom massings modelled in Phase 2 for the Phoenix and Washington D.C. climates.

\section{Results}

The case study of a typical eight-story office building served to demonstrate how the framework can aid decision-making throughout the design process, uncover design options that might not otherwise be considered, and help designers balance energy, embodied carbon, and cost considerations across climates.

\section{Phase 1: Pre-design Simulation for Phoenix}

Phase 1 simulated 10,368 combinations of basic building components and configurations. The results displayed by the parallel-axis plot shown in Figure 4 are initially convoluted due to the amount of data. Assuming that a design team might be interested in lowering EUI, the results were culled to include only design options below $61 \mathrm{kWh} / \mathrm{m}^{2} / \mathrm{yr}$. Selecting different inputs highlights (through colors) their influence on EUI and other outputs. Type 2 glazing (low SHGC) outperforms other options and the east and west WWR causes a notable decrease in EUI at $30 \%$ (Figure 5). 30\% north and south WWRs slightly outperform $70 \%$ WWRs. Steel and concrete structures outperform timber in terms of EUI, likely due to thermal mass. The east-west rectangular floorplate results in a slightly higher EUI than the north-south rectangular or square floorplates. Static and dynamic shading options result in slightly lower EUIs than no shading. Wall construction and roof $\mathrm{R}$-value have negligible effects.

Alternatively, a design team might consider the lowest embodied carbon options. Excluding design options above 260 metric tons of CO2eq shows that only options with a timber structure achieve this low of an initial carbon footprint after construction (Figure 6). However, if a team is truly interested in the building's total carbon footprint, they would also need to examine operational carbon emissions (tons $\mathrm{CO} 2 \mathrm{eq} / \mathrm{yr}$ ), which is completely dependent on the energy performance. Figure 7 shows only options below both 260 tons CO2eq in embodied carbon and 130 tons $\mathrm{CO} 2 \mathrm{eq} / \mathrm{yr}$ in operational carbon (the threshold for doubling the carbon footprint after two years of operation).

Most design teams are also likely looking to lower cost. Figure 8 shows options under $\$ 5,400,000$ in construction cost. Brick and precast concrete wall constructions, high WWRs, and timber structure options are eliminated.

\section{Phase 2: Refined Design for Phoenix}

Based on insights from Phase 1, a design team might decide on several parameters and refine the geometry. The results from Phase 1 suggest certain imperatives for an environmentally-conscious design. Type 2 glazing outperformed other options and is cheaper. A 30\% WWR for east and west façades also performed well. A timber structure significantly lowers embodied carbon. Using SIPs over brick or concrete walls can lower construction cost without compromising energy performance or carbon footprint. The roof R-value can be set to 20 because it has little effect and is the minimum required by code. Since the north-south rectangle and square floorplates performed better, this can guide bespoke massings. HVAC and lighting options can be introduced since the passive design parameters have been narrowed.

Thus, variable parameters for Phase 2 included four Rvalues for the SIPs walls from 13 to 33 , shallow or deep static shading, WWRs of $30 \%$ and $40 \%$ for north and south facades, LEDs or LEDs with daylight dimming, and code-compliant HVAC efficiency or HVAC with a COP of 5 and heat recovery. These parameters were applied to two custom massings loosely based on the bestperforming floorplates and WWRs (Figure 3).

From the results, daylight dimming and high-efficiency HVAC systems have significant impacts on EUI. The massing have mixed results (Figure 9) but they affect the impact of shading. The deep static shade has a small advantage over other options only when combined with stacked square floorplate, likely because the I-shape selfshades. The south and north WWRs have mixed results, and higher R-value wall options correspond to small decreases in EUI.

Phase 1: Pre-design Simulation for Washington D.C.

In direct contrast to the Phoenix results, Type 4 glazing (triple pane) and Type 3 glazing (double pane with a high SHGC) outperform other options in the Washington D.C. climate (Figure 10). Additionally, a 70\% southern WWR slightly lowers EUI instead of a $30 \%$ WWR. Steel and concrete structures also significantly outperform timber in terms of EUI, more so than in either Phoenix. The northsouth rectangle floorplate performs best by a tiny margin compared with the square and by a larger margin compared to the east-west rectangle. Like Phoenix, a 30\% northern WWR slightly lowers EUI, and a 30\% WWR on east and west facades vastly lowers EUI. Wall constructions, roof R-values, and shading have relatively little effect on EUI.

\section{Phase 2: Refined Design for Washington D.C.}

In contrast to the Phoenix scenario, Washington D.C.'s results in Phase 1 indicated that a concrete structure could be a better option over timber due to its substantial impact on EUI in this climate. Additionally, shading is eliminated, and new variable parameters include $60-70 \%$ southern WWRs, 30-40\% northern WWRs, and either Type 3 or Type 4 glazing. Two custom massings (Figure 2) prioritize a north-south rectangular floorplate and 
southern exposure. Other parameters like HVAC, lighting, the SIPs wall construction, and a static east-west WWR of $30 \%$ match the Phoenix settings.

Again, the efficient HVAC and daylight dimming options dominate the results. Massing also has a distinct impact, with the convex floorplate outperforming the stacked rectangle due to lower heating and lighting (Figure 11). This also affects glazing, with Type 4 slightly outperforming Type 3 on the stacked (Figure 12) but showing no distinct advantage on the convex massing. Wall R-values again have a subtle influence on EUI, and a smaller north WWR performs better. Southern WWR and roof $\mathrm{R}$-values had mixed results.

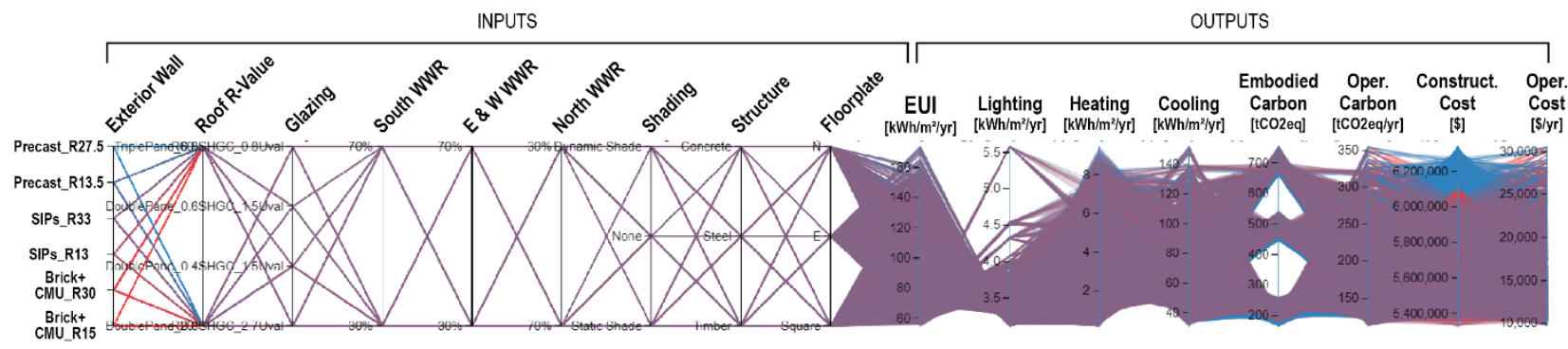

Figure 4: Parallel axis plot of results from initial simulations for the Phoenix climate.

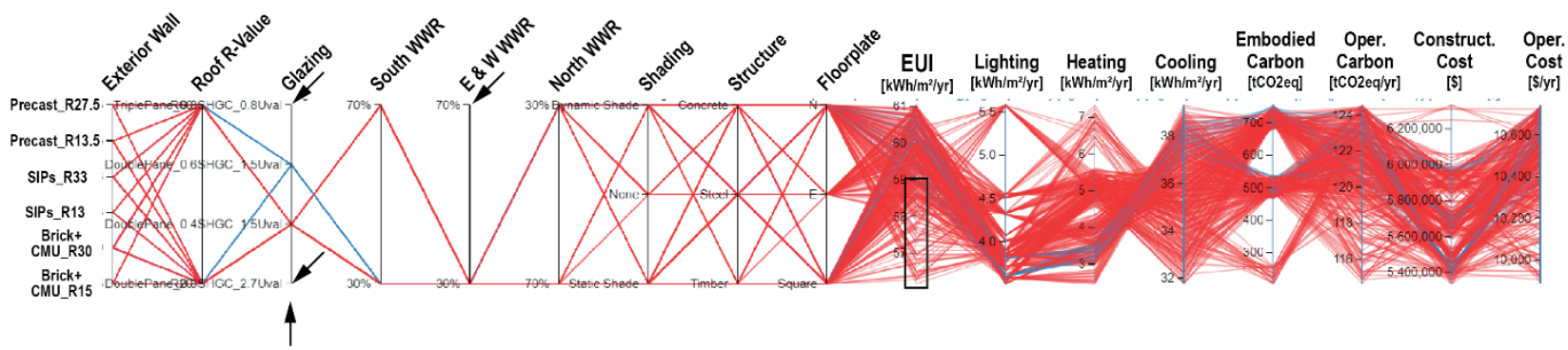

Figure 5: Effects of glazing and east-west WWR on EUI in Phoenix. Type 2 (red) distinctly outperforms Types 1 and 4 (which are eliminated) and Type 3 (blue). A 30\% east-west WWR outperforms $70 \%$ (eliminated).

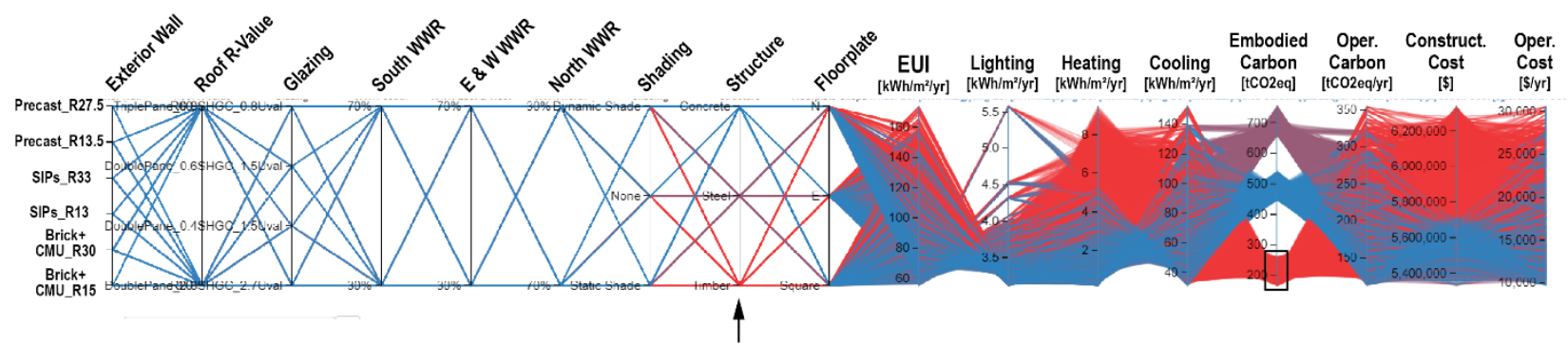

Figure 6: Effect of structure on embodied carbon. Timber (red) has significantly lower embodied carbon.

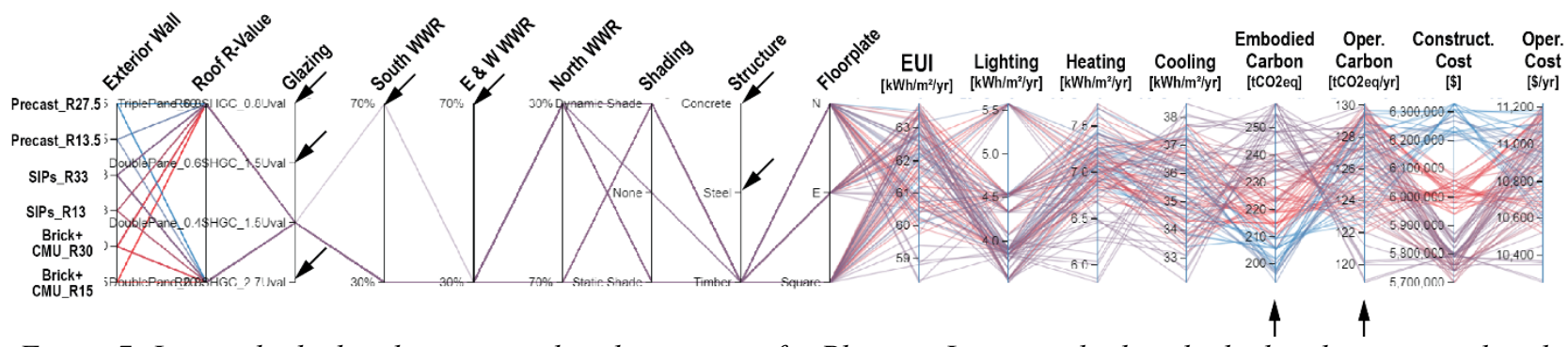

Figure 7: Low embodied and operational carbon options for Phoenix. Lowering both embodied and operational carbon eliminates several glazing options, high south and east-west WWRs and concrete and steel structure options. 


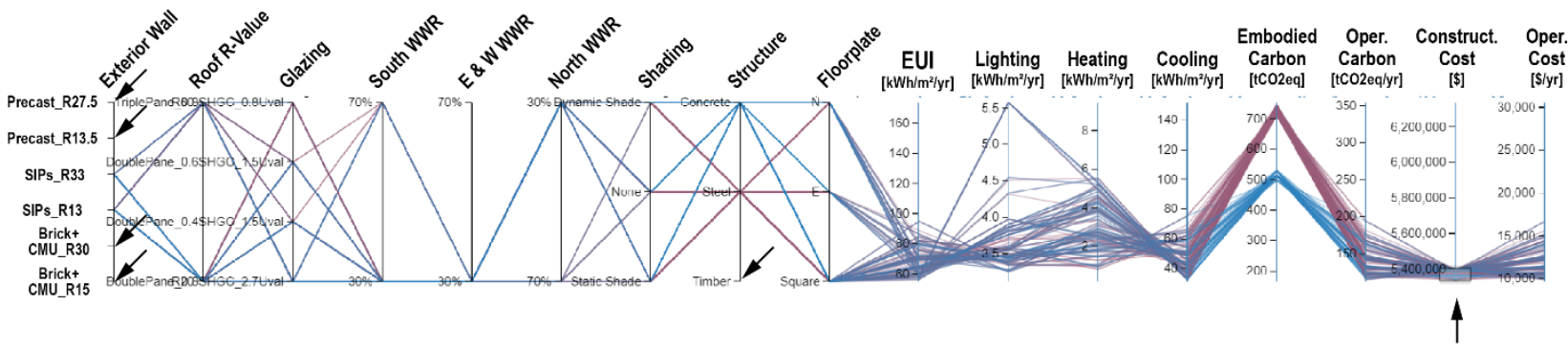

Figure 8: Lowest cost options for Phoenix. Only SIPs for wall construction and steel or concrete structure options

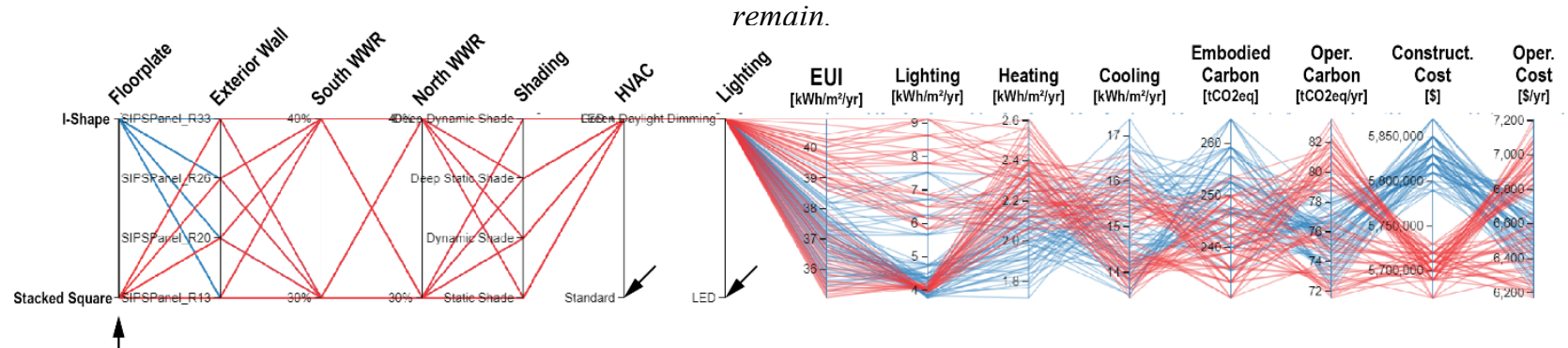

Figure 9: Lowest EUI results from Phase 2 for Phoenix. Only efficient HVAC and daylight dimming options remain, while the floorplate shapes have mixed impact on EUI.

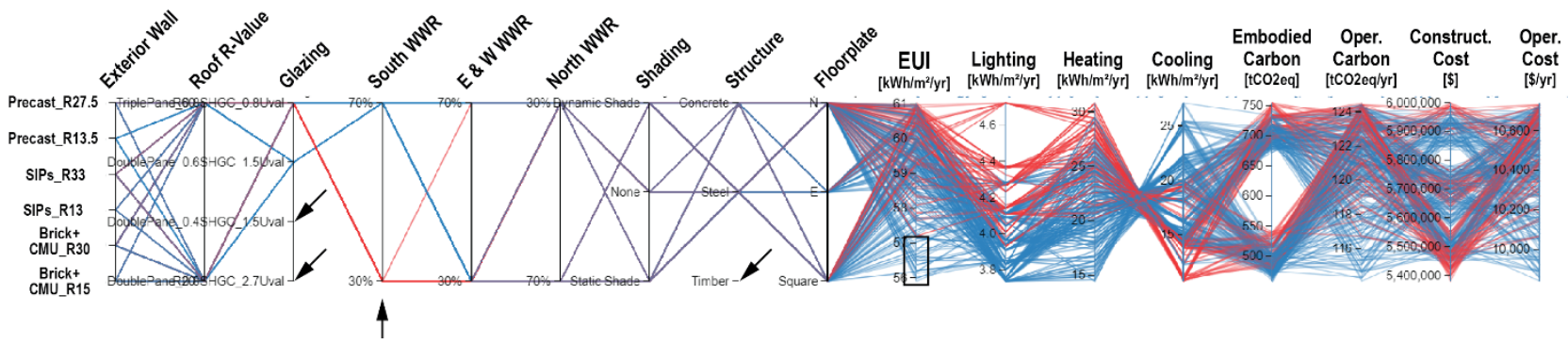

Figure 10: Lowest EUI results for the Washington D.C. climate. Notably, a 70\% southern WWR performs better, and Type 1 and 2 glazing as well as timber structure options are eliminated.

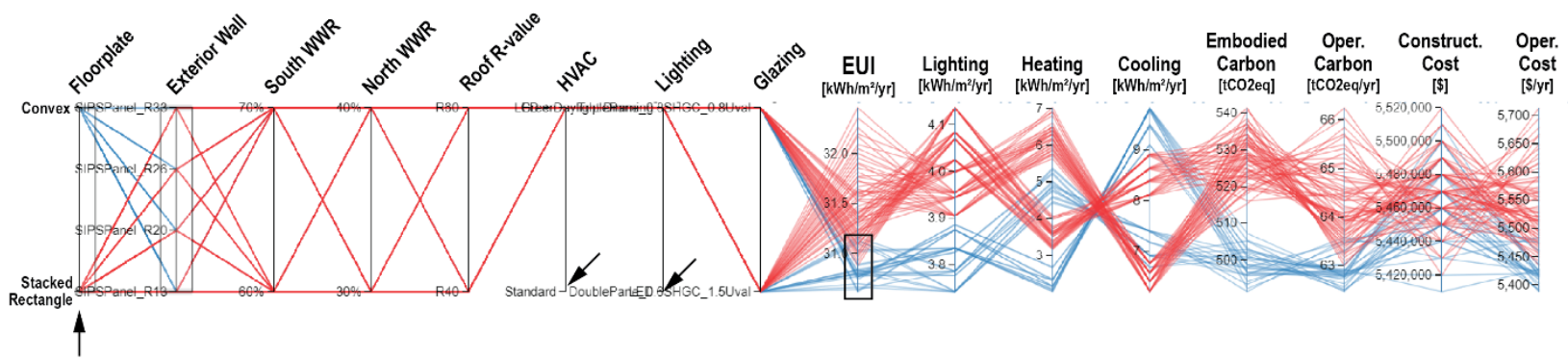

Figure 11: Lowest EUI results from Phase 2 for Washington D.C. The convex floorplate (blue) outperforms a stacked rectangle. Again, only efficient HVAC and daylight dimming options remain.

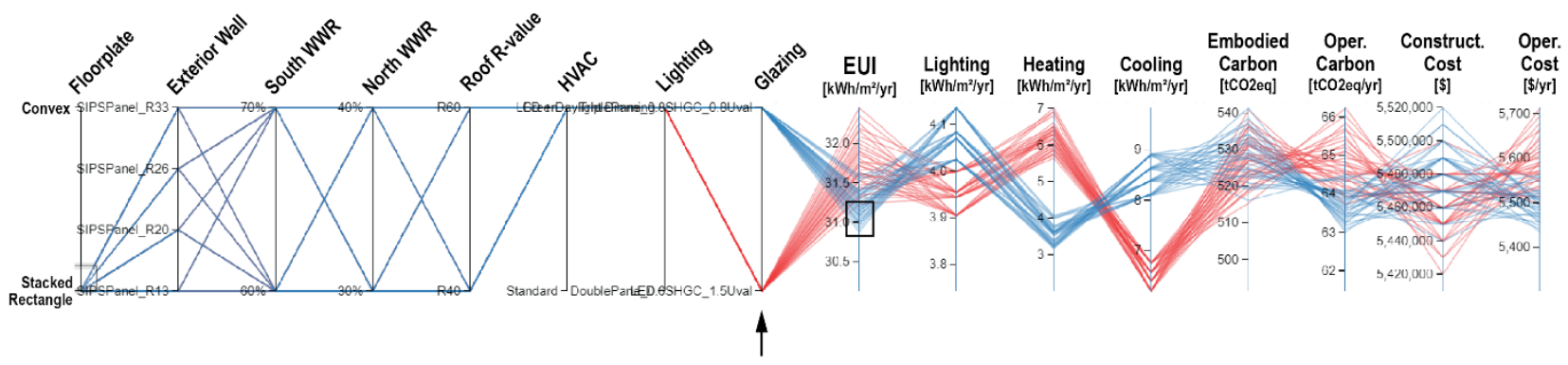

Figure 12: Lowest EUI results from Phase 2 for Washington D.C. for the stacked rectangle floorplate. Type 4 glazing (blue) outperforms Type 3 (red) only for this floorplate, but the results are mixed for the convex floorplate (not shown). 


\section{Discussion}

\section{Data Gathering}

This framework required the collection and assembly of many datasets around material thermal properties, embodied carbon, and construction and assembly costs, making it possible to simultaneously assess EUI, carbon footprint, and costs. This unique combination of data not only gives design teams a comprehensive look at their designs but reveals synergies between these typically isolated performance metrics. Like any simulation framework or tool, the accuracy is dependent on this data and assumptions. Publishing this database could make this framework more widely accessible and accurate.

\section{The Simulation Process}

The eight-story office building case study demonstrated how initial simulations can reveal the extents of the parametric design space for nascent designs and display key relationships for the design team. Notably, the interactive parallel-axis plot allows users to manipulate the results and define which performance metrics are most important to the project. If a design team is particularly concerned with energy performance, the results show that glazing WWRs and floorplate shape affect EUI differently depending on the climate. If the team is concerned about embodied carbon, timber becomes the best structural option. Lowering the cost reveals that a SIPs wall construction may be a better option than brick. Phase 2 simulations revealed both how HVAC efficiency and daylight dimming as well as geometric parameters have clear impacts on EUI, demonstrating the importance of early design simulations.

This combined mode of assessment also reveals some trade-offs between energy, carbon, and cost performance. For instance, embodied carbon pales in comparison to operational carbon after a few years for most design options. However, if operational energy is lowered, then embodied carbon has a larger impact on the building's lifecycle carbon footprint. Therefore, a design team aiming to build a low-carbon building must consider lowering energy use as a top priority before investing in low-carbon building materials.

The Phase 1 simulations for the two climates reinforced both the adaptability and effectiveness of the framework. The same parameters were considered for both Phoenix's and Washington D.C.'s climates, yet the framework revealed different optimal combinations for each climate. Low SHGC glazing performed better in the hotter climate of Phoenix but worse in Washington D.C. A high southern WWR was best in Washington D.C. but worse in Phoenix.

Phase 2 with the Phoenix and Washington D.C. climates displayed how this framework can accommodate more resolved designs that appear in later pre-design and schematic design phases. Custom massing designs were modelled in Rhino and inputted directly into the Grasshopper script for simulation, demonstrating the ease of use for architects. Notably, the results display a closer relationship between building performance and geometry, with the "I-Shape" massing reducing the need for shading or better glazing to improve performance and the
"Convex" massing distinctly outperforming a stacked massing. This provides actionable information for a design team. Once the field of parameters were narrowed, the framework revealed these subtler relationships.

Phase 2 simulations also displayed how this approach could work with rapidly changing designs. Considering that the simulation run times are close to instantaneous, a design team could potentially trial many more massing design variants in a feasible amount of time.

\section{Potential Improvements}

Although this first iteration demonstrated the breadth of the proposed framework, several improvements could make later iterations more robust and intelligent. First, some of the options could be expanded, like options to define open versus closed offices with different zones.

Secondly, a sensitivity analysis of the parameters could help designers better navigate the results of Phase 1. Design Explorer's parallel axis plot presents results succinctly, but the sheer number of options makes it difficult to easily draw conclusions for the next steps of the design. Including a baseline option that meets minimum code requirements could also provide design teams with a standard to compare iterations against.

The framework could also account for climate change impacts. A climate-morphing feature, like the CCWorldWeatherGen tool (Jentsch, James, Bourikas, and Bahaj, 2013), could help design teams consider the resilience and long-term effectiveness of design options in changing climate.

\section{Limitations of Embodied Carbon and Cost Estimates}

The current method for estimating embodied carbon in this version of the framework has some limitations. The calculation technique for the structure is less accurate for buildings with unusual massings that might require extra structure such as cantilevers or supports. In future iterations, a physics engine such as Karamba3D (Karamba3D, 2018) will likely be used to automatically generate structural configurations for a given building massing and structural material to produce more accurate carbon and cost estimations.

Embodied carbon estimates do not include items like interior partitions or substructure, which were excluded from this first iteration of the framework because they were considered relatively constant across all building types. Total embodied carbon is likely underestimated by the framework and thus should only be used for relative comparisons between design variants simulated through this framework. Future iterations will aim to refine the carbon estimation process.

Mass timber constructions in the simulation may be relatively inaccurate in terms of cost and carbon. Timber costs vary widely by region. Additionally, the ICE database does not account for the stored carbon in mass timber construction, which although subject to debate, could be substantial enough to offset embodied carbon from harvest and processing (Hafner and Schäfer, 2018). Further data could resolve these issues but also increase 
the complexity of the framework. Thus, simplicity was prioritized over accuracy of mass timber estimates.

This framework uses standard plug loads and occupancy schedules for offices as described in the SIA Merkblatt 2024 standard (2006), but occupant behavior can vary and heavily impact EUI. In the early design phase, detailed information on occupant behavior and use of the building is often unknown. Hence such variability seemed unnecessary to account for in an early design framework but should be considered in later design stages.

The framework also relies on national construction cost averages for the U.S. in 2018, but material and labor costs do vary based on the time period and location.

\section{Conclusion}

In this first iteration, this proposed decision-making framework has demonstrated its potential to address building simulation in the underserved but critical early design stages. By simulating energy performance, carbon footprint, and cost concurrently throughout the early stages of a design process, this framework highlights options and relationships that design teams may otherwise overlook. Its proactive, intelligent, and adaptable format make it ideal for use by architects during the rapid design development at the beginning of projects.

Given the sizable influence of early design decisions on the energy performance, carbon footprint, and cost of buildings, the proposed decision-making framework will enable design teams to develop optimal designs early on, saving time and money while producing higher performance buildings. This framework aims to strengthen architects' abilities to meet stringent demands on building performance and address the climate crisis.

\section{Acknowledgements}

The authors would like to thank the Cornell University David R. Atkinson Center for a Sustainable Future for funding this research.

\section{References}

Attia, S., Gratia, E., De Herde, A., and Hensen, J. L. M. (2012). Simulation-based decision support tool for early stages of zero-energy building design. Energy and Buildings, 49, 215.

Attia, S., Hensen, J. L. M., Beltrán, L., and Herde, A. D. (2012). Selection criteria for building performance simulation tools: contrasting architects' and engineers' needs. Journal of Building Performance Simulation, 5(3), 155-169.

Batueva, E., and Mahdavi, A. (2014). Assessment of a computational design environment with embedded simulation capability. eWork and eBusiness in Architecture, Engineering and Construction: ECPPM 2014, 197.

C40. (2018, August 23). C40: 19 Global Cities Commit to Make New Buildings "Net-Zero Carbon" by 2030. C40.

Dogan, T. (2018). Archsim Energy Modeling Software. Solemma LLC.
Dogan, T., and Reinhart, C. (2017). Shoeboxer: An algorithm for abstracted rapid multi-zone urban building energy model generation and simulation. Energy and Buildings, 140, 140-153.

Dogan, T., Reinhart, C., and Michalatos, P. (2016). Autozoner: an algorithm for automatic thermal zoning of buildings with unknown interior space definitions. Journal of Building Performance Simulation, 9(2), 176-189.

Eleftheriadis, S., Schwartz, Y., Raslan, R., Duffour, P., and Mumovic, D. (2018). Integrated building life cycle carbon and cost analysis embedding multiple optimisation levels. Building Simulation and Optimization.

Gordian. (2018). RSMeans Construction Cost Estimating Data.

Hafner, A., and Schäfer, S. (2018). Environmental aspects of material efficiency versus carbon storage in timber buildings. European Journal of Wood and Wood Products, 76(3), 1045-1059.

Hygh, J. S., DeCarolis, J. F., Hill, D. B., and Ranji Ranjithan, S. (2012). Multivariate regression as an energy assessment tool in early building design. Building and Environment, 57, 165-175.

Jentsch, M. F., James, P. A. B., Bourikas, L., and Bahaj, A. S. (2013). Transforming existing weather data for worldwide locations to enable energy and building performance simulation under future climates. Renewable Energy, 55, 514-524.

Jones, C., and Hammond, G. (2011, January). ICE (Inventory of Carbon and Energy) V2.0. Circular Ecology Ltd.

Karamba3D. (2018). Karamba3D - parametric engineering.

Ochoa, C. E., and Capeluto, I. G. (2009). Advice tool for early design stages of intelligent facades based on energy and visual comfort approach. Energy and Buildings, 41(5), $480-488$

Østergård, T., Jensen, R. L., and Maagaard, S. E. (2016). Building simulations supporting decision making in early design - A review. Renewable and Sustainable Energy Reviews, 61, 187-201.

Østergård, T., Jensen, R. L., and Maagaard, S. E. (2017). Early Building Design: Informed decision-making by exploring multidimensional design space using sensitivity analysis. Energy and Buildings, 142, 8-22.

Reinhart, C. F., Dogan, T., Ibarra, D., and Samuelson, H. W. (2012). Learning by playing - teaching energy simulation as a game. Journal of Building Performance Simulation, 5(6), 359-368.

Robert McNeel \& Associates. (2019). Rhino 6 for Windows. Rhinoceros.

Standard-Nutzungsbedingungen für die Energie-und Gebäudetechnik. (2006). Zurich: Swiss Society of Engineers and Architects.

Thornton Tomasetti. (2017). Design Explorer | CORE studio.

Thornton Tomasetti. (n.d.). Second Colibri Release | CORE studio. 